\title{
Planned Criterion Group Option Relationship
}

National Cancer Institute

\section{Source}

National Cancer Institute. Planned Criterion Group Option Relationship. NCI Thesaurus.

Code C93468.

A relationship between a planned criterion group and an option that can satisfy it, either a planned activity, a planned observation result or another planned criterion group, i.e. a relationship between a logical set of parenthesis and one of the options inside the parentheses. 